INFLAMMATORY BOWEL DISEASE

\title{
Defective mucosal T cell death is sustainably reverted by infliximab in a caspase dependent pathway in Crohn's disease
}

\author{
A Di Sabatino, R Ciccocioppo, B Cinque, D Millimaggi, R Morera, L Ricevuti, M G Cifone, \\ G R Corazza
}

Gut 2004;53:70-77

See end of article for authors' affiliations

Correspondence to: Professor G R Corazza Unità di

Gastroenterologia, IRCCS Policlinico San Matteo, Università di Pavia

Piazzale Golgi 5, 27100 Pavia, Italy; gr.corazza@ smatteo.pv.it

Accepted for publication 5 August 2003

\begin{abstract}
Background and aims: To verify whether targeting defective mucosal T cell death underlies the sustained therapeutic benefit of infliximab in Crohn's disease, we explored its in vivo proapoptotic effect after 10 weeks of treatment, and its in vitro killing activity on lamina propria T cells (LPT) and peripheral blood T cells (PBT), both isolated from Crohn's disease patients.

Methods: Endoscopic intestinal biopsies were collected from 10 Crohn's disease patients (six steroid refractory and four fistulising) before and after three consecutive infusions of infliximab, administered at week 0,2 , and 6 in a single intravenous dose $(5 \mathrm{mg} / \mathrm{kg})$, and from 10 subjects who proved to have functional diarrhoea. Apoptosis was determined in vivo by TUNEL assay, and in vitro by fluorescein isothiocyanate-annexin V/propidium iodide staining on LPT and PBT from Crohn's disease patients cultured with infliximab. The effect of the broad caspase inhibitor Z-VAD-FMK and the neutralising antiFas antibody ZB4 was tested in vitro on LPT and PBT treated with infliximab. Caspase-3 activity was determined by immunoblotting.

Results: In Crohn's disease patients, infliximab treatment induced a sustained LPT apoptosis, still evident four weeks after the last infusion. In vitro infliximab induced death of LPT from Crohn's disease patients occurred via apoptosis rather than necrosis. LPT showed a higher susceptibility to infliximab induced apoptosis than PBT in Crohn's disease patients. The signalling pathway underlying the restoration of infliximab induced LPT apoptosis occurred via the caspase pathway but not Fas-Fas ligand interaction in Crohn's disease.

Conclusions: These findings demonstrate that apoptosis is the major mechanism by which infliximab exerts its killing activity on LPT in Crohn's disease. The sustained LPT proapoptotic action of infliximab, which extends far beyond its circulating half life, may be responsible for the sustained remission induced in Crohn's disease patients by infliximab retreatment.
\end{abstract}

A $\mathrm{s}$ intestinal inflammation is accompanied by excessive immune cell survival in Crohn's disease, ${ }^{12}$ agents that have the capacity to increase T cell apoptosis, as shown recently in experimental colitis for blockade of interleukin (IL) $-12^{3}$ or IL-6 trans signalling pathway, ${ }^{4}$ may be particularly effective as a form of therapy for this condition. Promoting immune cell apoptosis has been proposed as a major mechanism for the therapeutic benefit of infliximab, ${ }^{56}$ a chimeric monoclonal antibody to human tumour necrosis factor $\alpha$ (TNF- $\alpha)$, shown to be efficacious in controlled trials both in steroid refractory and fistulising Crohn's disease. ${ }^{78}$

However, a number of questions remain. To date, the proapoptotic activity of infliximab has been explored in vitro on peripheral monocytes from Crohn's disease patients ${ }^{5}$ and the CD3/CD28 activated Jurkat T cell line, ${ }^{6}$ and only in vivo on lamina propria T cells (LPT), ${ }^{6}$ which are the main target of infliximab action. ${ }^{9}$ Furthermore, as infliximab has also been shown to kill TNF expressing cells by inducing lysis via complement activation or antibody dependent cell mediated cytotoxicity, ${ }^{10}$ it should be determined whether infliximab exerts its killing activity exclusively via apoptosis in Crohn's disease.

In the present study, we tested the in vitro infliximab induced death of $\mathrm{T}$ cells isolated from intestinal lesions of Crohn's disease patients. In addition, to investigate the signalling machinery transducing infliximab action in Crohn's disease, caspase-3 activity was determined, and a broad caspase inhibitor and an anti-Fas blocking antibody were added to LPT cultured with infliximab.

\section{PATIENTS AND METHODS \\ Patients}

Ten consecutive patients with a firm diagnosis of Crohn's disease (mean age 34.2 years (range 22-51)) were candidates for treatment with infliximab either because they were steroid refractory (six patients were unresponsive to corticosteroids up to $40 \mathrm{mg}$ prednisone equivalent per day for eight weeks or more with stable doses for at least two weeks) or affected by fistulising disease (four patients were refractory to standard therapy with antibiotics or to azathioprine for six or more months, with stable doses for at least eight weeks before inclusion). Diagnosis of Crohn's disease was ascertained according to the usual clinical criteria, ${ }^{11}$ and the site and extent of disease were confirmed by endoscopy,

\footnotetext{
Abbreviations: CDAl, Crohn's disease activity index; EDTA, ethylenediamine tetraacetic acid; FasL, Fas ligand; FCS, fetal calf serum; FITC, fluorescein isothiocyanate; IL, interleukin; LPT, lamina propria T cells; PBS, phosphate buffered saline; PBT, peripheral blood T cells; PDAl, perianal disease activity index; $\mathrm{PI}$, propidium iodide; TNF, tumour necrosis factor; TUNEL, terminal deoxynucleotidyl transferase mediated digoxigenin-deoxyuridine triphosphate nick end labelling; Z-VAD-FMK, Z-Val-Ala-Asp(OMe)-monofluoroketone
} 
histology, and enteroclysis in all patients. None of the patients had previously undergone resective surgery, had been treated with cyclosporin or methotrexate, or presented symptomatic stenosis, strictures, or abscesses.

\section{Treatment and assessment}

Crohn's disease patients received three consecutive infusions of infliximab (Remicade, Schering Plough, Milan, Italy) administered at week 0,2 , and 6 at a dose of $5 \mathrm{mg} / \mathrm{kg}$. Concomitant treatment with 5-aminosalicylic acid or sulphasalazine was continued. In the six steroid refractory patients, steroids were tapered and then discontinued. No patient received azathioprine, cyclosporin, or methotrexate throughout the study.

Full colonoscopy and ileoscopy were performed immediately before the start of therapy and 10 weeks later, with collection of multiple size appropriate ileal and colonic biopsy specimens. Before infliximab infusion, biopsies were taken from macroscopically inflamed areas, and after treatment were collected from the same areas as before treatment. Both ileal and colonic biopsy specimens were also taken from 10 subjects (mean age 38.2 years (range 21-62)) who were found to have functional diarrhoea at the end of their diagnostic workup.

Some of the biopsy samples from Crohn's disease patients, before and after infliximab treatment, and controls were immediately fixed in $10 \%$ neutral buffered formalin, embedded in paraffin within 24 hours, and processed according to standard methods for histology and immunohistochemistry. Other samples from patients before treatment and controls were used to obtain purified LPT suspensions. Peripheral blood T cells (PBT) were isolated from ethylenediamine tetraacetic acid (EDTA) treated blood, drawn from Crohn's disease patients before infliximab treatment and from controls. Each patient gave informed consent to the study.

Disease activity was assessed by Crohn's disease activity index (CDAI). Patients with scores below 150 were classified as being in remission whereas those with scores above 450 had severe disease. ${ }^{11}$ In the group with fistulising disease, we also measured the perianal disease activity index (PDAI) which is a composite score ranging from 0 to 20, with higher scores indicating more severe disease. ${ }^{12} \mathrm{CDAI}$ and PDAI were determined within one week before infusion and after 10 weeks. Clinical response was defined as a decrease in CDAI by 70 points or more in the group of steroid refractory patients, or as a reduction in the number, size, drainage, or discomfort associated with fistula(s) in fistulising disease. Complete remission was defined, respectively, as a CDAI $<150$ points or as cessation of fistula drainage and total closure of all fistulas. All clinical features of Crohn's disease patients are reported in table 1.

\section{In vivo experiments}

\section{TUNEL detection}

For the "in situ" detection of apoptotic cells, terminal deoxynucleotidyl transferase mediated digoxigenin-deoxyuridine triphosphate nick end labelling (TUNEL) was used, according to a method modified by Gavrieli and colleagues, ${ }^{13}$ using a peroxidase ApopTag Kit (Oncor, Gaithesburg, Maryland, USA). Sections were digested with proteinase K $20 \mu \mathrm{g} / \mathrm{ml}$ (Sigma Chemical Co., St. Louis, Missouri, USA) for 15 minutes at room temperature and then washed in tap water. Endogenous peroxidase was quenched by 3\% hydrogen peroxidase for 20 minutes and then washed in phosphate buffered saline (PBS). After equilibration, sections were incubated in a humidified chamber with terminal deoxynucleotidil transferase enzyme for one hour at $37^{\circ} \mathrm{C}$. Sections were subsequently soaked in stop wash buffer for 30 minutes, rinsed in PBS, and thereafter incubated with antidigoxigenin peroxidase in a humidified chamber for 30 minutes, followed by addition of diaminobenzidine and hydrogen peroxide for 1-3 minutes to allow colour development on apoptotic nuclei. Finally, sections were counterstained with Harris' haematoxylin. As a positive control, an Apoptag control slide was used whereas the negative control was performed by omission of the terminal deoxynucleotidil transferase enzyme on seriate sections.

\section{CD3 detection}

To determine whether TUNEL positive cells were T lymphocytes, seriate sections were processed with a monoclonal antiCD3 antibody (Calbiochem, San Diego, California, USA). Pretreatment was performed by incubation for 30 minutes at room temperature with pronase $0.01 \mathrm{~g} \%$ (Calbiochem).

\section{Quantitation of positive cells}

Using conventional light microscopy, tissue sections were examined in a blinded fashion by an expert observer. Counts were performed at a constant magnification $(\times 1000)$ by a differential count of at least 500 lamina propria mononuclear cells and the results expressed as a percentage of positive cells.

\section{In vitro experiments}

Cell isolation

Lamina propria lymphocytes were isolated as previously described. ${ }^{14}$ Briefly, biopsy specimens were placed in sterile medium (PBS calcium and magnesium free, supplemented with $100 \mathrm{U} / \mathrm{ml}$ penicillin, $100 \mu \mathrm{g} / \mathrm{ml}$ streptomycin, and $5 \%$ fetal calf serum (FCS)). The epithelial layer was removed with $1 \mathrm{mM}$ EDTA (Sigma) and $1 \mathrm{mM}$ dithiothreitol (Sigma). After continuous agitation for one hour at $37^{\circ} \mathrm{C}$, the supernatant was removed and the remaining tissue was treated with type 1 A collagenase $128 \mathrm{U} / \mathrm{ml}$ (Sigma) for one hour with continuous agitation at $37^{\circ} \mathrm{C}$. The crude cell suspension was allowed to stand for five minutes to permit sedimentation of debris. Cells from the supernatant were layered on Ficoll-Hypaque solution (Pharmacia Fine Chemicals, Pharmacia Inc., Uppsala, Sweden) to isolate lamina propria lymphocytes by a density gradient method. Peripheral blood lymphocytes were isolated from heparinised peripheral blood by Lymphoprep gradient centrifugation (Nicamed, Oslo, Norway), further purified by plastic adherence to remove monocytes. For T cell purification, both lamina propria and peripheral blood lymphocytes were subjected to positive selection using magnetic beads charged with anti-human CD3 monoclonal antibody (Clone HIT3a; Becton Dickinson Co., San Jose, California, USA) on a VarioMACS magnetic cell separator (Miltenyi Biotec Inc., Auburn, California, USA). Resulting cell populations averaged $95 \%$ viability and exceeded $94 \%$ purity.

\section{Cell culture}

Freshly isolated Crohn's disease and control LPT and PBT were incubated at $37^{\circ} \mathrm{C}$ in a $5 \% \mathrm{CO}_{2}$ atmosphere for 18 hours with anti-TNF- $\alpha$ antibody (infliximab; Schering-Plough) added to the culture medium at different concentrations ( 1 and $5 \mu \mathrm{g} / \mathrm{ml}$ ) or its isotype matched control (human IgGl). In parallel experiments, cells treated with infliximab at a concentration of $5 \mu \mathrm{g} / \mathrm{ml}$ or IgGl were preincubated with $50 \mu \mathrm{mol} / \mathrm{L} \mathrm{Z}$-Val-Ala-Asp(OMe)-monofluoroketone (Z-VADFMK; Calbiochem), an irreversible inhibitor of caspases, including caspase-1, caspase-3, caspase- 4 , and caspase- $7,{ }^{15}$ or with $1 \mu \mathrm{g} / \mathrm{ml}$ ZB4 anti-Fas blocking antibody (Ancell Corporation, Bayport, Minnesota, USA). Cells were incubated with inhibitors for 30 minutes before addition of infliximab or IgGl. Human Jurkat T cells, cultured in RPMI 1640 
Table 1 Clinical data for patients with Crohn's disease

\begin{tabular}{|c|c|c|c|c|c|c|c|c|c|c|c|}
\hline $\begin{array}{l}\text { Patient } \\
\text { No }\end{array}$ & $\begin{array}{l}\text { Age } \\
\text { (y) }\end{array}$ & Sex & $\begin{array}{l}\text { Indication for } \\
\text { treatment }\end{array}$ & Disease location & $\begin{array}{l}\text { Disease } \\
\text { duration (y) }\end{array}$ & $\begin{array}{l}\text { Previous } \\
\text { treatment }\end{array}$ & $\begin{array}{l}\text { CDAl } \\
(0 \mathrm{wk})\end{array}$ & $\begin{array}{l}\text { CDAI } \\
\text { (10 wk) }\end{array}$ & $\begin{array}{l}\text { PDAI } \\
\text { (0 wk) }\end{array}$ & $\begin{array}{l}\text { PDAl } \\
\text { (10 wk) }\end{array}$ & $\begin{array}{l}\text { Response to } \\
\text { treatment }\end{array}$ \\
\hline 1 & 30 & M & $\begin{array}{l}\text { Steroid } \\
\text { refractory }\end{array}$ & Ileocolonic & 2 & Steroids & 421 & 287 & - & - & Partial \\
\hline 2 & 35 & $\mathrm{~F}$ & $\begin{array}{l}\text { Steroid } \\
\text { refractory }\end{array}$ & Gastroileocolonic & 3 & $\begin{array}{l}\text { Steroids, } \\
\text { AZA }\end{array}$ & 354 & 238 & - & - & Partial \\
\hline 3 & 24 & $\mathrm{~F}$ & $\begin{array}{l}\text { Steroid } \\
\text { refractory }\end{array}$ & Ileocolonic & 7 & Steroids & 236 & 137 & - & - & Complete \\
\hline 4 & 22 & M & $\begin{array}{l}\text { Fistulising } 1 \\
\text { perianal }\end{array}$ & Ileocolonic & 3 & $\begin{array}{l}\text { Antibiotics, } \\
\text { steroids }\end{array}$ & 298 & 165 & 9 & 0 & Complete \\
\hline 5 & 39 & M & $\begin{array}{l}\text { Fistulising } 3 \\
\text { perianal }\end{array}$ & Colonic & 5 & $\begin{array}{l}\text { AZA, } \\
\text { antibiotics }\end{array}$ & 263 & 188 & 12 & 5 & Partial \\
\hline 6 & 51 & $\mathrm{~F}$ & $\begin{array}{l}\text { Steroid } \\
\text { refractory }\end{array}$ & Ileal & 10 & Steroids & 392 & 334 & - & - & Absent \\
\hline 7 & 40 & $\mathrm{~F}$ & $\begin{array}{l}\text { Fistulising } 4 \\
\text { perianal }\end{array}$ & Ileocolonic & 6 & $\begin{array}{l}\text { AZA, } \\
\text { antibiotics }\end{array}$ & 312 & 201 & 13 & 5 & Partial \\
\hline 8 & 42 & $\mathrm{~F}$ & $\begin{array}{l}\text { Steroid } \\
\text { refractory }\end{array}$ & Ileocolonic & 14 & $\begin{array}{l}\text { Steroids } \\
\text { antibiotics }\end{array}$ & 283 & 194 & - & - & Partial \\
\hline 9 & 31 & M & $\begin{array}{l}\text { Steroid } \\
\text { refractory }\end{array}$ & Ileal & 7 & Steroids & 309 & 140 & - & - & Complete \\
\hline 10 & 28 & $\mathrm{~F}$ & $\begin{array}{l}\text { Fistulising } 1 \\
\text { perianal }\end{array}$ & Colonic & 4 & Antibiotics & 275 & 131 & 11 & 0 & Complete \\
\hline
\end{tabular}

containing 5\% FCS, were incubated with the mouse monoclonal anti-human Fas antibody ( $1 \mu \mathrm{g} / \mathrm{ml}$, clone DX2; Calbiochem), an inducer of apoptosis in Fas expressing cells, and used as a positive control of ZB4 anti-Fas blocking action. Quantitation of apoptosis in cell cultures was performed by flow cytometry with fluorescein isothiocyanate (FITC)-annexin V and propidium iodide (PI) staining.

\section{Apoptosis evaluation by FITC-annexin V and PI binding}

Apoptosis was quantified using FITC-annexin V and PI, according to the manufacturer's protocol (ApoDETECT FITCAnnexin V Kit; Zymed Laboratories Inc., San Francisco, California, USA). Cells were stained with $5 \mu \mathrm{l}$ of FITCannexin V diluted 1:10 in buffer, and $2.5 \mu \mathrm{l}$ of PI. After incubation for 15 minutes, cells were analysed by flow cytometry with standard FACScan equipment (Becton Dickinson Co.). Cells undergoing the early stage of apoptosis were stained with FITC-annexin $\mathrm{V}$ alone (percentage of apoptosis). Late apoptotic cells were distinguished by their ability to take up both FITC-annexin V and PI (percentage of dead cells). Live cells were those staining negatively for FITCannexin V and PI (percentage of cell survival). ${ }^{16}$ Cells permeabilised with $0.1 \%$ saponin were used as controls for PI positive cells.

\section{Immunoblotting}

Cells were washed in PBS and lysed in ice cold lysing buffer containing $20 \mathrm{mM} \mathrm{pH} \mathrm{7.6} \mathrm{Tris} \mathrm{HCl}, 150 \mathrm{mM}$ sodium chloride, $1 \mathrm{mM}$ phenylmethylsulphonyl fluoride, $1 \%$ Triton-X, $1 \mathrm{mM}$ EDTA, $2 \mathrm{mM}$ sodium orthovanadate, $10 \mu \mathrm{g} / \mathrm{ml}$ pepstatin, $10 \mu \mathrm{g} / \mathrm{ml}$ leupeptin, and $10 \mu \mathrm{g} / \mathrm{ml}$ aprotinin (Sigma). Protein concentration in each lysate was measured using the Pierce protein assay (Pierce, Rockford, Illinois, USA). Equivalent amounts of protein ( $12 \mu \mathrm{g}$ ) were fractioned on $12.5 \%$ sodium dodecyl sulphate-polyacrylamide gels and electrotransferred to nitrocellulose membranes (Bio-Rad Laboratories, Hercules, California, USA). Membranes were blocked with 5\% non-fat dry milk, followed by incubation for 90 minutes at room temperature with the mouse monoclonal antibody anticaspase-3 (Alexis Co., Lausen, Switzerland). Membranes were washed several times with TTBS and incubated for 90 minutes at room temperature with the affinity purified secondary horseradish peroxidase conjugate antimouse
IgG-horseradish peroxidase (Santa Cruz Biotechnology, Santa Cruz, California, USA). After extensive washing, the reaction was developed by enhanced chemiluminescent staining (Super Signal; Pierce). Human Jurkat $\mathrm{T}$ cells, cultured for seven hours in the presence of $2.5 \mu \mathrm{g} / \mathrm{ml}$ actinomycin D (Sigma), were used as positive controls.

\section{Statistical analysis}

Data were analysed using the GraphPad Prism statistical PC program (GraphPad Software, San Diego, California, USA) by means of the non-parametric Mann-Whitney U test. One way analysis of variance (ANOVA test) was used to define differences in the percentage of apoptotic cells obtained in cultures treated with various concentrations of infliximab. A value of $p<0.05$ was considered statistically significant.

\section{RESULTS}

\section{Clinical response to treatment}

All but one Crohn's disease patient experienced clinical improvement after 10 weeks of treatment with infliximab, as shown in table 1 . The median pretreatment CDAI (303) decreased significantly $(\mathrm{p}<0.001)$ to 191 after 10 weeks. In the subgroup of fistulising patients, the pretreatment median PDAI (11.5) decreased to 2.5 after 10 weeks. Infusion of infliximab was well tolerated; only one patient experienced an allergic reaction during the third infusion.

\section{In vivo induction of LPT apoptosis}

Apoptosis in the lamina propria of Crohn's disease patients, before and after 10 weeks of treatment with infliximab, and in controls was detected using the TUNEL technique. Figure 1 shows that in comparison with Crohn's disease patients before treatment (fig lA), in whom TUNEL positivity was almost exclusively found at the level of crypt epithelial cells, a considerable proportion of lamina propria mononuclear cells were TUNEL positive in Crohn's disease patients after treatment (fig $1 \mathrm{~B}$ ) and in controls (fig lC). Figure ID confirms that the median percentages of TUNEL positive lamina propria mononuclear cells significantly increased in Crohn's disease patients after infliximab treatment from $0.58 \%$ (range $0.12-1.07$ ) to $3.09 \%$ (range $1.49-6.64$ ). Patients showing a complete response to treatment showed the highest levels of lamina propria mononuclear cell apoptosis while the one non-responder had the lowest percentage of 

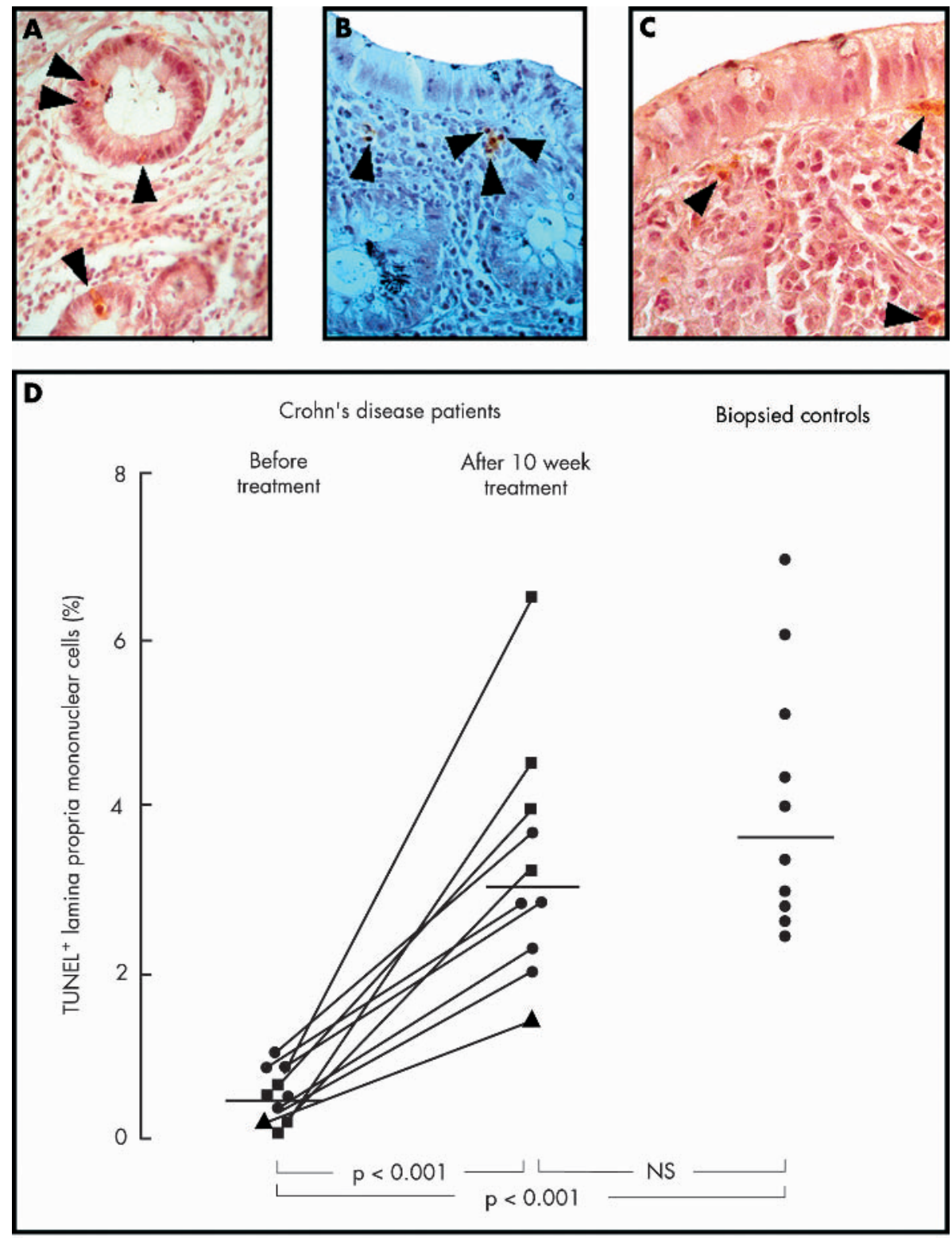

Figure 1 Detection of apoptotic cells by terminal deoxynucleotidyl transferase mediated digoxigenin-deoxyuridine triphosphate nick end labelling (TUNEL) staining in Crohn's disease patients, before (A) and after 10 weeks of treatment with infliximab (B), and in normal intestinal mucosa (C). In Crohn's disease patients before treatment, TUNEL positivity is evident at the level of epithelial (arrows) but not lamina propria mononuclear cells while in Crohn's disease patients after treatment and in controls, a considerable proportion of lamina propria mononuclear cells are TUNEL positive (arrows) (original magnification, $\times 400$ ). (D) Percentage of TUNEL positive lamina propria mononuclear cells in 10 patients with Crohn's disease before and after 10 weeks of treatment with infliximab, and in 10 biopsied controls. The four patients with a complete response to treatment and the one nonresponder are indicated with different symbols (filled squares and triangles, respectively). Horizontal bars represent median values.

TUNEL positive cells. No significant difference was found between Crohn's disease patients after infliximab and controls (median 3.69\% (range 2.57-7.54)). To determine whether TUNEL positive cells were T lymphocytes, seriate sections were also processed with anti-CD3. We observed that CD3 positive cells showed good colocalisation with TUNEL positivity. The percentage of LPT apoptosis was not affected by the duration or dose of steroid therapy.

\section{In vitro induction of LPT apoptosis}

To further verify that infliximab exerted its killing activity on LPT, these cells were isolated from intestinal lesions of Crohn's disease patients and from control bowel, cultured in the presence of infliximab, and analysed by flow cytometry with FITC-annexin V and PI staining. Parallel experiments were also carried out on PBT from both Crohn's disease patients and controls. In fig 2, representative results of Crohn's disease patients show that, in comparison with LPT cultured with IgGl (fig 2A), LPT cultured in the presence of $5 \mu \mathrm{g} / \mathrm{ml}$ (fig 2B) showed a higher percentage of apoptotic cells (FITC-annexin V positive/PI negative). Parallel results for $\mathrm{PBT}$ are depicted in fig $2 \mathrm{C}$ and 2D. Again, PBT cultured in the presence of infliximab (fig 2D) proved more susceptible to apoptosis than those incubated with IgGl (fig 2C), although PBT were found to be much less sensitive than LPT (fig 2B) to infliximab action.

As shown in fig 2B, the low percentage of FITC-annexin $\mathrm{V}$ positive/PI positive cells indicated that infliximab induced apoptotic, but not necrotic, cell death in LPT from Crohn's disease patients. This is confirmed in fig 3, which shows the 


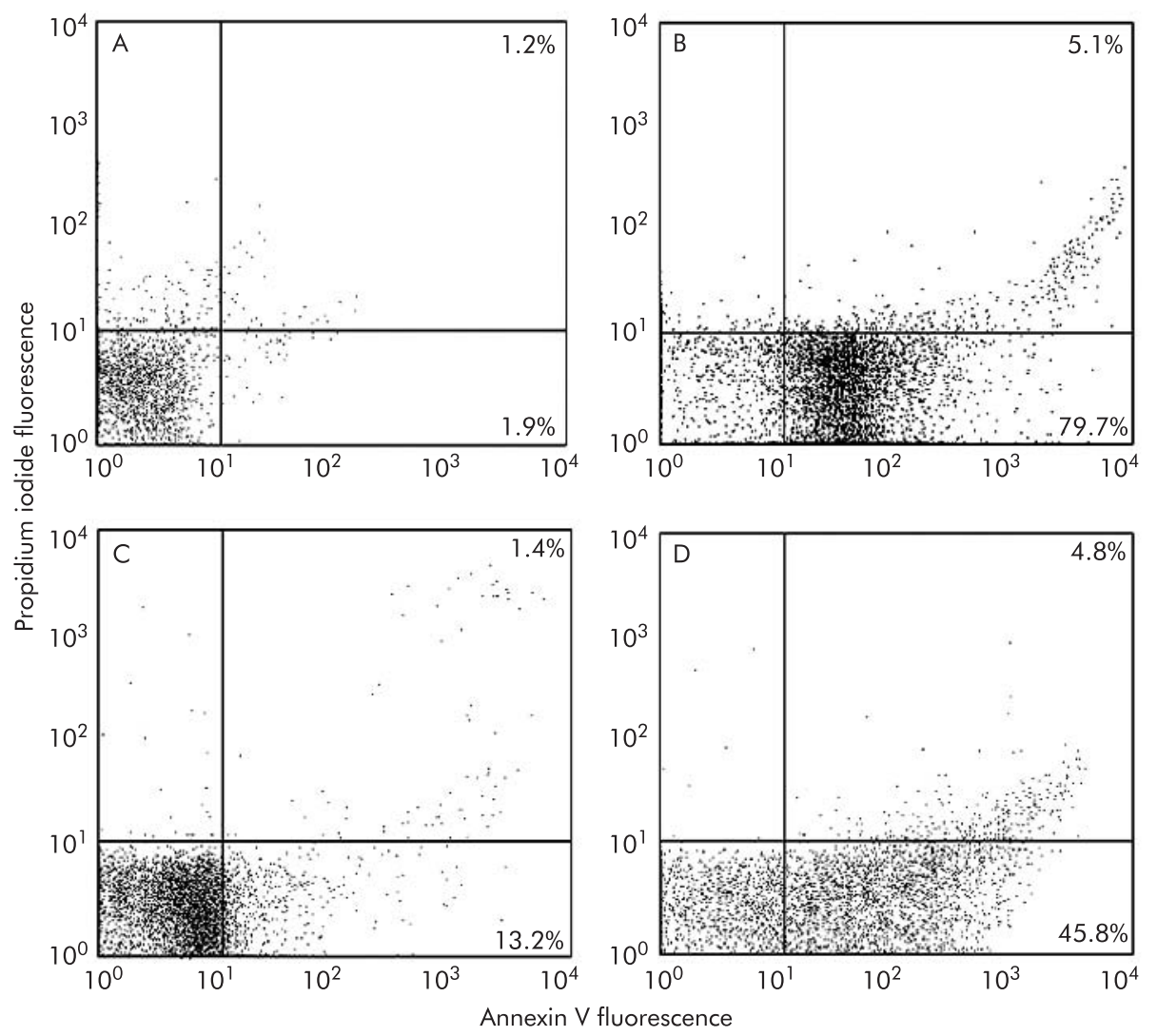

Figure 2 Flow cytometric analysis of fluorescein isothiocyanate (FITC)-annexin V binding and propidium iodide (PI) uptake of Crohn's disease lamina propria T cells (LPT) (A, B) and peripheral blood T cells (PBT) (C, D) cultured with infliximab. LPT and PBT were incubated with lgG1 as control antibody ( $A$ and $C$, respectively) and with infliximab at a concentration of $5 \mu \mathrm{g} / \mathrm{ml}$ (B and D, respectively). The lower left quadrant of each panel shows live cells (FITC-annexin V negative/PI negative), the lower right quadrant represents apoptotic cells (FITC-annexin V positive/PI negative), and the upper right quadrant contains the non-viable dead cells (FITC-annexin V positive/PI positive). Numbers within the dot plots represent the percentages of apoptotic and dead cells. The data, which are representative of experiments performed in all patients with Crohn's disease, show the higher percentage of apoptotic LPT treated with infliximab (B) in comparison with those cultured with the lgG1 isotype control (A), and the higher susceptibility of LPT (B) to undergo infliximab induced apoptosis compared with PBT (D). The low percentages of double stained cells allowed us to exclude necrotic membrane damage as a consequence of infliximab treatment.

poor percentages of LPT undergoing necrosis after incubation with increasing concentrations ( 1 and $5 \mu \mathrm{g} / \mathrm{ml}$ ) of infliximab (mean $2.4(1.2) \%$ and mean $3.9(1.8) \%$, respectively) in comparison with the considerable proportion of cells undergoing apoptosis (mean 20.7 (7.4)\% and mean 77.3 (11.9)\%, respectively).

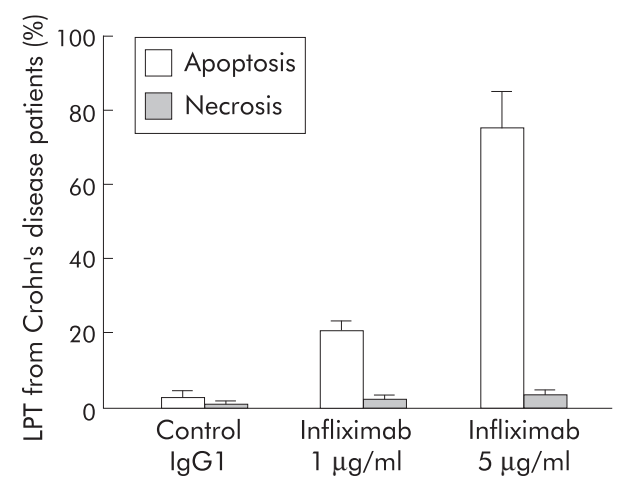

Figure 3 Percentages of apoptotic and necrotic lamina propria T cells (LPT) from Crohn's disease patients, assessed by flow cytometric analysis of fluorescein isothiocyanate-annexin V/propidium iodide binding. LPT were incubated with $\operatorname{lgG} 1$ as a control antibody and with infliximab at concentrations of 1 and $5 \mu \mathrm{g} / \mathrm{ml}$. Results are mean (SD).
As shown in fig 4, in Crohn's disease patients the percentage of apoptotic LPT (mean 2.4 (1.3)\%) was significantly raised by incubation with increasing concentrations of 1 and $5 \mu \mathrm{g} / \mathrm{ml}$ infliximab to $20.7(7.4) \%(\mathrm{p}<0.01)$ and $77.3(11.9) \%$ $(\mathrm{p}<0.0001)$, respectively. As for PBT, the percentage of apoptotic cells (mean 13.8 (3.1)\%) was increased to 17.5 (5.8)\% and $42.1(6.7) \%$, but only after $5 \mu \mathrm{g} / \mathrm{ml}$ infliximab did this difference reach statistical significance $(p<0.01)$. In experiments performed in the presence of control antibody, significantly lower apoptosis was observed in Crohn's LPT compared with PBT (mean $2.4 \%$ and $13.8 \%$, respectively; $\mathrm{p}<0.01$ ). In control LPT and PBT (fig 4), infliximab increased the percentage of apoptotic cells from mean $3.5(4.7) \%$ to $19.4(6.7) \%$ and $45.1(7.3) \%$, and from mean $15.1(3.6) \%$ to $18.8(5.8) \%$ and $41.2(6.4) \%$, respectively, with a significant difference $(p<0.01)$ only between cells cultured with control antibody and $5 \mu \mathrm{g} / \mathrm{ml}$ infliximab. When comparing control LPT and PBT, no significant difference was found in the percentage of apoptosis, either in the presence of control antibody or infliximab.

To verify which pathway was involved in LPT infliximab induced apoptosis in Crohn's disease, we tested the possible effect of both the antagonistic ZB4 anti-Fas blocking antibody $^{14}$ and the broad spectrum caspase inhibitor Z-VAD-FMK, ${ }^{15}$ and investigated the activation state of the effector caspase-3 in LPT treated with infliximab. Figure 5A shows that blocking Fas-Fas ligand (FasL) interaction by 

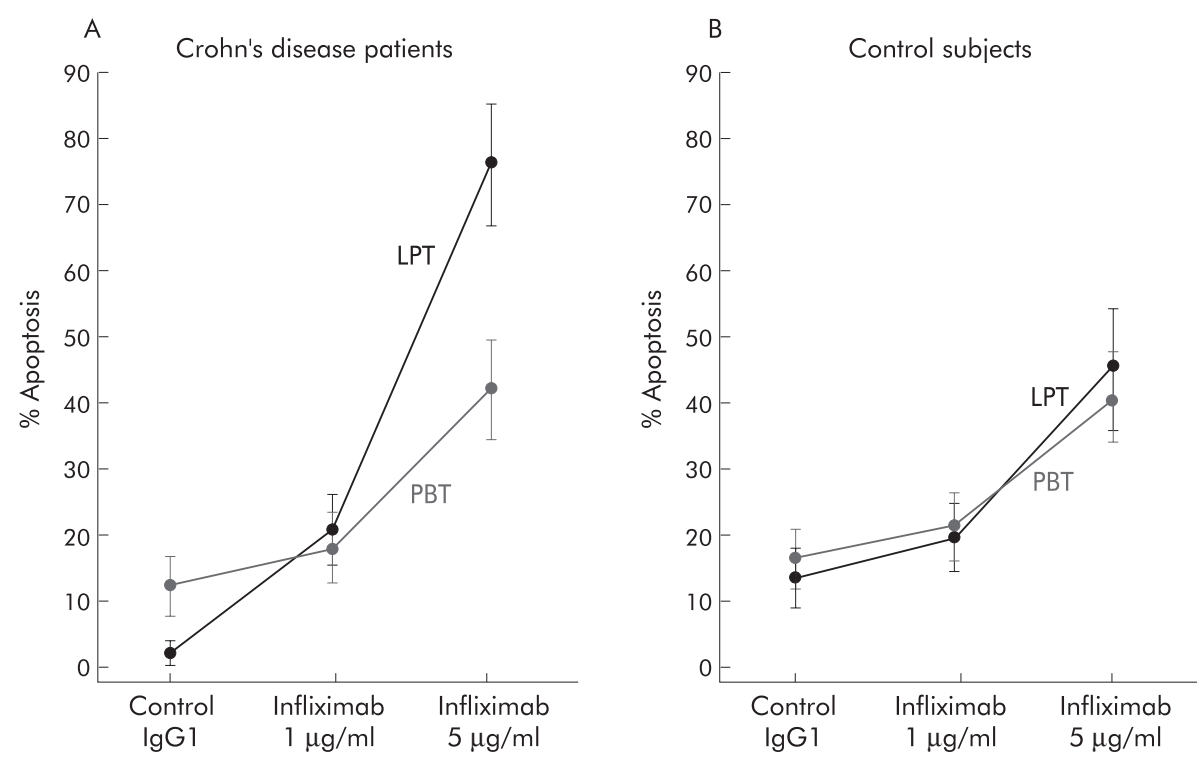

Figure 4 Effect of infliximab on lamina propria T cells (LPT) and peripheral blood T cells (PBT) obtained from 10 Crohn's disease patients and 10 control subjects. Cells were cultured with infliximab added to the culture medium at different concentrations ( 1 and $5 \mu \mathrm{g}$ / $\mathrm{ml}$ ) or its isotype matched control (human lgG1). The percentage of apoptotic cells was assayed by flow cytometric analysis of fluorescein isothiocyanate-annexin $\mathrm{V} /$ propidium iodide binding. Results are mean (SD).

preincubation with a neutralising anti-Fas antibody did not diminish LPT apoptosis induced by infliximab in Crohn's disease patients. Fas expressing Jurkat $\mathrm{T}$ cells, stimulated to undergo programmed death with an apoptosis inducer antiFas antibody, were used as a positive control of ZB4 anti-Fas blocking action (fig 5A). In contrast, caspase inhibition by Z-VAD-FMK significantly decreased infliximab induced apoptosis of LPT in Crohn's disease patients from mean $77.3(11.9) \%$ to 6.1 (2.1)\% (fig 5B). Caspase dependent infliximab induced apoptosis was also observed in Crohn's disease patients at the level of PBT (from mean 42.1 (6.7)\% to $5.2(1.9) \%$ ), and in control subjects at the level of LPT (from mean 45.1 (7.3)\% to $4.9(1.8) \%$ ) and PBT (from mean 41.2 $(6.4) \%$ to $7.1(2.2) \%)$. In fig 6, representative results of Crohn's disease patients show that, in comparison with LPT cultured with IgGl, LPT cultured with increasing concentrations of infliximab ( 1 and $5 \mu \mathrm{g} / \mathrm{ml}$ ) manifested an enhanced caspase- 3 activation, as shown by the dose dependent increase in its active form, the p12 subunit.

\section{DISCUSSION}

In the current study, we investigated whether targeting defective mucosal $\mathrm{T}$ cell death underlies the sustained therapeutic benefit of infliximab in Crohn's disease and explored for the first time the capacity of infliximab to induce death of $\mathrm{T}$ cells isolated from intestinal lesions of Crohn's disease patients. We demonstrated that infliximab acts by inducing apoptosis but not necrosis of LPT and that the signalling pathway underlying this action is not mediated by a Fas dependent mechanism but requires caspase activation.

To study the relationship between the clinical response to infliximab treatment and in vivo LPT apoptosis, intestinal biopsies taken during endoscopies performed immediately before and after 10 weeks of treatment were analysed for apoptotic cells using the TUNEL technique. Interestingly, LPT apoptosis after therapy was found to be not only significantly increased but normalised after 10 weeks of treatment. This finding adds further to our knowledge of the in vivo proapoptotic activity of infliximab. The latter is not only characterised by a rapid onset of action, which has been reported to appear within 24 hours after treatment, ${ }^{6}$ but just as important it induces a sustained LPT proapoptic action which is still detectable four weeks after the last infusion. This sustained action may well be responsible for the durable remission induced in Crohn's disease patients by infliximab retreatment every eight weeks. ${ }^{17}$ Experiments to investigate the pattern of LPT apoptosis during the retreatment period are at present under investigation in our laboratory. The relationship between LPT apoptosis and clinical response observed in Crohn's disease patients after treatment further confirms the role of infliximab in exerting its therapeutic efficacy by targeting defective $\mathrm{T}$ cell apoptosis in this condition.

An additional aim of the present study was to better elucidate the mechanisms by which infliximab exerts its therapeutic benefit. TNF- $\alpha$ is considered to be centrally involved in the pathogenesis of Crohn's disease and to play a pivotal role in the inflammatory cascade. ${ }^{18}$ As infliximab neutralises TNF- $\alpha$ by blocking the soluble cytokine and by binding to transmembrane TNF- $\alpha$, this mechanism has been claimed to explain its clinical efficacy. ${ }^{19}$ However, sole suppression of TNF- $\alpha$ may not be sufficient to justify all of the clinical improvement observed, as a recent study with pentoxifylline, another TNF- $\alpha$ suppressor which acts by increasing CAMP concentration, ${ }^{20}$ failed to be effective in refractory Crohn's disease. ${ }^{21}$ This finding together with the evidence that therapeutic effects of infliximab extend far beyond its circulating half life, ${ }^{22}$ strongly suggest that its action may be more complex than simply neutralising TNF- $\alpha$.

Scallon and colleagues ${ }^{10}$ were the first to shed more light on further mechanisms by which infliximab might work, suggesting that anti-TNF- $\alpha$ antibodies mediate lysis of murine myeloma cells expressing mutant human TNF- $\alpha$ by both complement activation and antibody dependent cellular cytotoxicity. Subsequently, infliximab has been reported to induce apoptosis of peripheral monocytes from patients with steroid refractory Crohn's disease. ${ }^{5}$ Although monocytes together with macrophages are known to be the main producers of soluble TNF- $\alpha_{,}^{23}{ }^{24}$ since infliximab seems to exert its proapoptotic action by binding to membrane associated TNF- $\alpha,{ }^{5}$ attention has been focused on T lymphocytes, which express high amounts of this transmembrane form. ${ }^{25}$ Recently, ten Hove et al showed that LPT, which are known to be resistant to apoptosis in Crohn's disease, ${ }^{26}$ manifested a rapid increase in TUNEL positivity after infliximab infusion in steroid refractory patients. ${ }^{6}$ However, in that study the proapoptotic action of infliximab was not tested directly on mucosal $\mathrm{T}$ cells but on the Jurkat T cell line, and the possible occurrence of target cell lysis, as a consequence of infliximab action, has not been excluded by ten Hove and colleagues. ${ }^{6}$ 

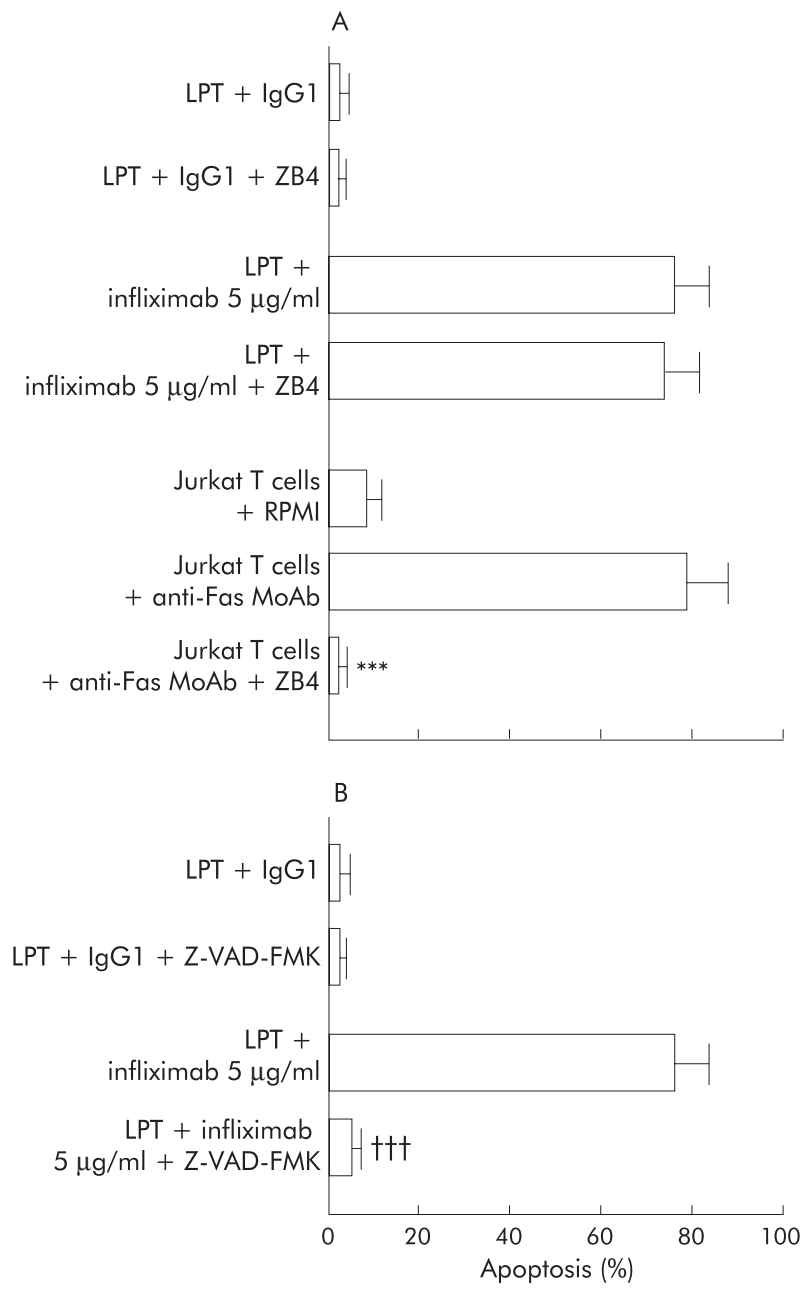

Figure 5 Involvement of caspase signalling pathway but not Fas-Fas ligand interaction in the transduction of infliximab induced apoptosis in Crohn's disease lamina propria T cells (LPT). (A) LPT from intestinal lesions of 10 Crohn's disease patients were treated with infliximab at a concentration of $5 \mu \mathrm{g} / \mathrm{ml}$ or lgGl isotype control, after preincubation with ZB4 anti-Fas blocking antibody. Jurkat T cells cultured in RPMI 1640 medium and stimulated to undergo apoptosis by incubation with the mouse monoclonal antihuman Fas antibody (MOAb), an inducer of apoptosis in Fas expressing cells, were used as a positive control of ZB4 anti-Fas blocking action. (B) LPT isolated from intestinal lesions of 10 Crohn's disease patients and treated with infliximab at a concentration of $5 \mu \mathrm{g} / \mathrm{ml}$ or $\mathrm{lgGl}$ isotype control were preincubated with Z-Val-AlaAsp(OMe)-monofluoroketone (Z-VAD-FMK) caspase inhibitor.

Quantitation of apoptotic cells in cell cultures was performed by flow cytometry with fluorescein isothiocyanate-annexin $\mathrm{V}$ and propidium iodide staining. Results are mean (SD). ${ }^{* * *} \mathrm{p}<0.0001$ versus Jurkat $T$ cells cultured in the absence of ZB4 anti-Fas blocking antibody; †††p $<0.0001$ versus cells cultured in the absence of Z-VAD-FMK.

In our study, double staining with FITC-annexin V and PI, which makes it possible to quantify both the percentages of apoptotic and damaged cells, ${ }^{16}$ demonstrated that the proportions of necrotic cells were insignificant compared with those of cells undergoing programmed death. Although we cannot exclude the fact that a complement dependent cytotoxicity has a role in mediating in vivo the killing action of infliximab on LPT, our in vitro system being complement free, we can state that antibody dependent cellular cytotoxicity does not play a crucial role in infliximab induced lymphocyte death. The discrepancy between our results and those obtained by Scallon and colleagues ${ }^{10}$ probably lies in the use of different targets of infliximab action-human LPT and murine myeloma cells expressing mutant human TNF,

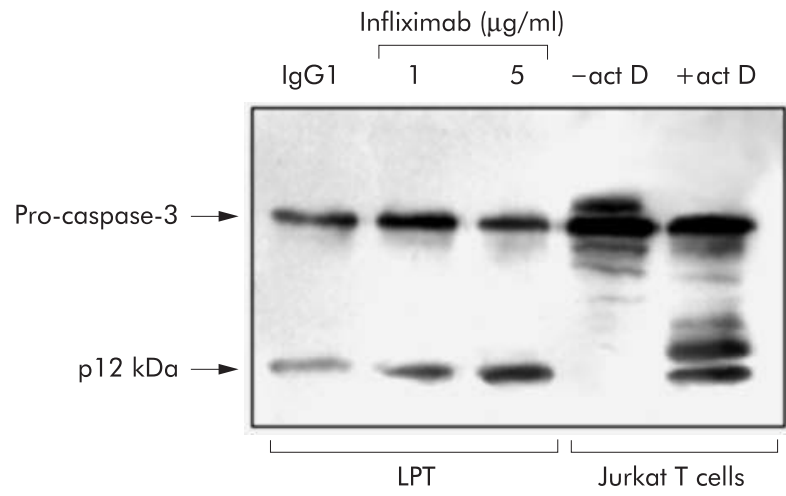

Figure 6 Involvement of caspase-3 in infliximab induced apoptosis in Crohn's disease lamina propria T cells (LPT). LPT from intestinal lesions of Crohn's disease patients were treated with infliximab at different concentrations (1 and $5 \mu \mathrm{g} / \mathrm{ml}$ ) or lg $\mathrm{G} 1$. Jurkat T cells, cultured for seven hours in the absence or presence of $2.5 \mu \mathrm{g} / \mathrm{ml}$ actinomycin $D$ (act D), were used as controls. Caspase-3 activity was determined by immunoblot analysis. The blot shows two bands of 32 and $12 \mathrm{kDa}$, corresponding to the proform and active form of caspase-3, respectively. Data are representative of experiments performed in all patients with Crohn's disease.

respectively. It is important that in Crohn's disease, infliximab induced death of LPT occurs via apoptosis rather than necrosis. This ensures a more effective and rapid action in restoring immune homeostasis in the inflamed intestine, avoiding the release of inflammatory mediators or cellular debris, which might amplify rather than hamper the abnormal immune response.

The significantly lower apoptosis observed in LPT in comparison with PBT from Crohn's disease patients would seem to reinforce the hypothesis that insufficient apoptosis is an intrinsic mucosal defect in Crohn's disease. Accordingly, when we compared the effect of infliximab on LPT with that on PBT, in Crohn's disease we observed a lower susceptibility of PBT to undergo apoptosis. This low susceptibility is in good agreement with the previously reported absence of a significant decrease in peripheral blood mononuclear cell count after infliximab treatment. ${ }^{6}$ Moreover, reduced interferon $\gamma$ and TNF- $\alpha$ production by stimulated lamina propria mononuclear cells in the absence of changes in the proportion of peripheral blood mononuclear cells producing the same cytokines has recently been reported in Crohn's disease patients after infliximab therapy. ${ }^{27}$ Together, these data further strengthen the hypothesis that infliximab exerts a local anti-inflammatory action in the bowel mucosa without systemic immune suppression, thus explaining why opportunistic infections were not observed in Crohn's disease patients treated with this drug. ${ }^{28}$

The higher susceptibility of Crohn's LPT compared with PBT supports the hypothesis of ten Hove and colleagues ${ }^{6}$ on the basis of their in vitro experiments on CD3/CD28 stimulated and resting Jurkat $\mathrm{T}$ cells: the infliximab proapoptotic action is largely $\mathrm{T}$ cell activation dependent. Similarly, the percentage of Crohn's apoptotic LPT was significantly higher than that of controls, in which the increase in LPT and PBT apoptosis, evident after incubation of $5 \mu \mathrm{g} / \mathrm{ml}$ infliximab, may represent a non-specific effect of this high dose.

It is known that Fas-FasL expression is closely related to the process of lymphocyte activation, and that their reciprocal interaction is crucial for its control and termination. ${ }^{29}$ While the Fas-FasL system has been shown to mediate intestinal lymphocyte apoptosis in normal intestine, ${ }^{30} \mathrm{~T}$ cells grown from Crohn's disease lesions were resistant to Fas mediated apoptosis. ${ }^{31}$ Our present results indeed confirm that blocking 
Fas-FasL interaction by addition of a neutralising antibody against Fas did not affect infliximab induced LPT apoptosis. As it has recently been reported that caspases have a critical role in the regulation of LPT apoptosis, ${ }^{32}$ and that infliximab induced peripheral monocyte apoptosis requires the proteolytic activation of initiator caspase- 8 and caspase-9, which subsequently activates the effector caspase- $3,{ }^{5}$ we investigated the role of caspase- 3 in the transduction of $\mathrm{T}$ cell apoptotic signalling machinery triggered by infliximab in Crohn's disease. The observation that induction of LPT apoptosis by infliximab causes caspase- 3 activation, together with the evidence of marked inhibition of $\mathrm{T}$ cell apoptosis in the presence of the broad spectrum caspase inhibitor Z-VADFMK, ${ }^{15}$ suggests that the action of infliximab strictly depends on caspase activation. The evidence that caspases are subject to genetic polymorphism ${ }^{33}{ }^{34}$ strengthens the key role of pharmacogenomics in infliximab therapy. ${ }^{35}$

In conclusion, if our study shows that a caspase dependent apoptosis is the major form of cell death occurring in LPT after infliximab treatment, we cannot exclude the fact that other mechanisms may be responsible for the beneficial effects of infliximab in Crohn's disease. Interestingly, the recent demonstration that infliximab exerts its therapeutic action in myelodysplastic syndromes and rheumatoid arthritis associated chronic anaemia by protecting bone marrow erythroid cells from apoptosis ${ }^{36}{ }^{37}$ suggests a putative role of this agent in ameliorating Crohn's disease associated chronic anaemia by a reverse mechanism to that exerted against $\mathrm{T}$ cells. Hence it is conceivable that infliximab could act in a pro or antiapoptotic manner according to the type of target cell. Furthermore, it should be noted that the signalling pathways transducing the proapoptotic action of infliximab are different in different cell systems-Fas dependent in rheumatoid synovial cells ${ }^{38}$ or Fas independent in Crohn's peripheral monocytes ${ }^{5}$ and LPT.

Dissecting the complex machinery of the action of infliximab will provide interesting answers to the numerous questions raised by its successful use in Crohn's disease and will suggest its potential therapeutic implications in any pathological conditions sustained by a defect in $\mathrm{T}$ cell apoptosis.

\section{Authors' affiliations}

A Di Sabatino, R Morera, L Ricevuti, G R Corazza, Gastroenterology Unit, IRCCS Policlinico S Matteo, University of Pavia, Pavia, Italy B Cinque, D Millimaggi, M G Cifone, Department of Experimental Medicine, University of L'Aquila, L'Aquila, Italy

R Ciccocioppo, Department of Internal Medicine, University of L'Aquila, L'Aquila, Italy

\section{REFERENCES}

1 Di Sabatino A, Corazza GR. Surviving too long in Crohn's disease. Gut 2001;49:6-8.

2 Sturm A, Fiocchi C. Life and death in the gut: more killing, less Crohn's. Gut 2002;50:148-9.

3 Fuss IJ, Marth T, Neurath MF, et al. Anti-interleukin 12 treatment regulates apoptosis of Th $1 \mathrm{~T}$ cells in experimental colitis in mice. Gastroenterology 1999; 117:1078-88.

4 Atreya R, Mudter J, Finotto S, et al. Blockade of interleukin 6 trans signaling suppresses T-cell resistance against apoptosis in chronic intestinal inflammation: evidence in Crohn disease and experimental colitis in vivo. Nat Med 2000;6:583-8

5 lügering A, Schmidt $M$, Lügering $N$, et al. Infliximab induces apoptosis in monocytes from patients with chronic active Crohn's disease by using a caspase-dependent pathway. Gastroenterology 2001;121:1145-57.

6 ten Hove T, van Montfrans C, Peppelenbosch MP, et al. Infliximab treatment induces apoptosis of lamina propria T lymphocytes in Crohn's disease. Gut 2002;50:206-11.

7 Targan SR, Hanauer SB, van Deventer SJH, et al. A short-term study of chimeric monoclonal antibody CA2 to tumor necrosis factor $\alpha$ for Crohn's disease. N Engl J Med 1997;337:1029-35.

8 Present DH, Rutgeerts P, Targan SR, et al. Infliximab for the treatment of fistulas in patients with Crohn's disease. N Engl J Med 1999;340:1398-405.
9 van Deventer SJH. Transmembrane TNF- $\alpha$, induction of apoptosis, and the efficacy of TNF-targeting therapies in Crohn's disease. Gastroenterology, $2001 ; 121 ; 1242-6$

10 Scallon BJ, Moore MA, Trinh $\mathrm{H}$, et al. Chimeric anti-TNF- $\alpha$ monoclonal antibody cA2 binds recombinant transmembrane TNF- $\alpha$ and activates immune effector functions. Cytokine 1995;7:251-9.

11 Best WR, Becktel JM, Singleton JW, et al. Development of a Crohn's disease activity index: National Cooperative Crohn's Disease Study. Gastroenterology 1976:70:439-44.

12 Irvine EJ. Usual therapy improves perianal Crohn's disease as measured by a new disease activity index. McMaster IBD Study Group. J Clin Gastroenterol 1995;20:27-32.

13 Gavrieli Y, Sherman Y, Ben-Sasson SA. Identification of programmed cell death in situ via specific labeling of nuclear DNA fragmentation. J Cell Biol 1992;119:493-501.

14 Di Sabatino A, Ciccocioppo R, D'Alò S, et al. Intraepithelial and lamina propria lymphocytes show distinct patterns of apoptosis, whereas both the populations are active in Fas-based cytotoxicity in coeliac disease. Gut $2001 ; 49: 380-6$.

15 Pronk GJ, Ramer K, Amiri P, et al. Requirement of an ICE-like protease for induction of apoptosis and ceramide generation by REAPER. Science 1996;271:808-10.

16 van Engeland M, Nieland LW, Ramaehers FCS, et al. Annexin V-affinity assay: a review on an apoptosis detection system based on phosphatidylserine exposure. Cyłometry 1998:31:1-9.

17 Hanquer SB, Feagan BG, Lichtenstein GR, et al. Maintenance infliximab for Crohn's disease: the ACCENT I randomised trial. Lancet 2002;359:1541-9.

18 Papadakis KA, Targan SR. Role of cytokines in the pathogenesis of inflammatory bowel disease. Annu Rev Med 2000;51:289-98.

19 Papadakis KA, Targan SR. Tumor necrosis factor: biology and therapeutic inhibitors. Gastroenterology 2000;119:1148-57

20 Reimund JM, Dumont S, Muller CD, et al. In vitro effects of oxpentifylline on inflammatory cytokine release in patients with inflammatory bowel disease. Gut 1997:40:475-80.

21 Bauditz J, Haemling J, Ortner M, et al. Treatment with tumour necrosis factor inhibitor oxpentifylline does not improve corticosteroid dependent chronic active Crohn's disease. Gut 1997:40:470-4.

22 Mouser JF, Hyams JS. Infliximab: a novel chimeric monoclonal antibody for the treatment of Crohn's disease. Clin Ther 1999;21:932-42.

23 Breese EJ, Michie CA, Nicholls S, et al. Tumour necrosis factor alphaproducing cells in the intestinal mucosa of children with inflammatory bowel disease. Gastroenterology 1994;106:1455-66.

24 Reinecker HC, Steffen M, Witthoeft T, et al. Enhanced secretion of tumour necrosis factor-alpha, IL-6, and IL- 1 beta by isolated lamina propria mononuclear cells from patients with ulcerative colitis and Crohn's disease. Clin Exp Immunol 1993;94:174-81.

25 Aversa J, Punnonen J, de Vries JE. The 26-kD transmembrane form of tumor necrosis factor alpha on activated $\mathrm{CD} 4^{+} \mathrm{T}$ cell clones provides a costimulatory signal for human B cell activation. J Exp Med 1993;177:1575-85.

26 Boirivant M, Marini M, Di Felice G, et al. Lamina propria T cells in Crohn's disease and other gastrointestinal inflammation show defective $C D 2$ pathwayinduced apoptosis. Gastroenterology 1999;1 16:557-65.

27 Cornillie F, Shealy D, D'Haens G, et al. Infliximab induces potent antiinflammatory and local immunomodulatory activity but no systemic immune suppression in patients with Crohn's disease. Aliment Pharmacol Ther 2001;15:463-73.

28 Rutgeerts P, D'Haens G, Targan S, et al. Efficacy and safety of retreatment with anti-tumor necrosis factor antibody (infliximab) to maintain remission in Crohn's disease. Gastroenterology 1999;117:761-9.

29 Dhein J, Walczac H, Baumler C, et al. Autocrine T-cell suicide mediated by APO-1 (Fas/CD95). Nature 1995;373:438-41.

30 Boirivant M, Pica R, De Maria R, et al. Stimulated human lamina propria T cells manifest enhanced Fas-mediated apoptosis. J Clin Invest 1996;98:2616-22.

31 Ina K, Itoh J, Fukushima K, et al. Resistance of Crohn's disease T cells to multiple apoptotic signals is associated with a $\mathrm{Bcl}-2 / \mathrm{Bax}$ mucosal imbalance. J Immunol 1999;163:1081-90.

32 Sturm A, Mohr S, Fiocchi C. Critical role in the regulation of apoptosis and proliferation of mucosal T cells. Gastroenterology 2002;122:1334-45.

33 Kondo S, Shinomura Y, Miyazaki Y, et al. Mutations of the bak gene in human gastric and colorectal cancers. Cancer Res 2000:60:4328-30.

34 Komaki S, Kohno M, Matsuura N, et al. The polymorphic 43Thr bcl-2 protein confers relative resistance to autoimmunity: an analytical evaluation. Hum Genet 1998;103:435-40.

35 Shetty A, Forbes A. Pharmacogenomics of response to anti-tumor necrosis factor therapy in patients with Crohn's disease. Am J Pharmacogenomics 2002;2:215-21.

36 Stasi R, Amadori S. Infliximab chimaeric anti-tumour necrosis factor alpha monoclonal antibody treatment for patients with myelodysplastic syndromes. Br J Haematol 2002;1 16:334-7.

37 Papadaki HA, Kritikos HD, Valatas V, et al. Anemia of chronic disease in rheumatoid arthritis is associated with increased apoptosis of bone marrow erythroid cells: improvement following anti-tumor necrosis factor- $\alpha$ antibody therapy. Blood 2002;100:474-82.

38 Oshima S, Mima T, Sasai M, et al. Tumour necrosis factor- $\alpha$ (TNF- $\alpha$ ) interferes with Fas-mediated apoptotic cell death on rheumatoid arthritis (RA) synovial cells: a possible mechanism of rheumatoid synovial hyperplasia and a clinical benefit of anti-TNF $\alpha$ therapy for RA. Cytokine 2000;12:281-8. 